\title{
USING A HYBRID DECISION-MAKING MODEL TO EVALUATE THE SUSTAINABLE DEVELOPMENT PERFORMANCE OF HIGH-TECH LISTED COMPANIES
}

\author{
Yih-Chang OU \\ Department of Finance, Ling Tung University, 1 Ling Tung Road, \\ Nantun, Taichung, 40852, Taiwan, R.O.C. \\ E-mail:ycou@teamail.ltu.edu.tw \\ Received 08 February 2015; accepted 17 October 2015
}

\begin{abstract}
In this study, we use a triple bottom-line concept including economic, social and environmental performance as the sustainable development performance evaluation categories for companies. Moreover, an integrated model based on grey relational analysis, decision-making trial and evaluation laboratory, analytic network process and the technique for order preference by similarity to ideal solution is proposed for solving a corporate sustainability performance evaluation and ranking problem. In order to verify the proposed model, we adopt 34 high-tech listed companies in Taiwan as the research object to measure companies' sustainable development performance and ranking in 2013. The results can be used as an important basis for management decision-making, and can also serve as reference for banks and investors when developing investment strategy.
\end{abstract}

Keywords: sustainable development, performance evaluation, grey relational analysis, decision-making trial and evaluation laboratory, analytic network process, technique for order preference by similarity to ideal solution.

JEL Classification: C44, D81, L21, L25, M14.

\section{Introduction}

Performance measurement represents the operating performance of a business. Operating performance is not only able to show whether a company has good or poor performance, but also predicts future growth and development. The financial information of a company is used to assess operating performance. Therefore, financial ratio analysis has been commonly used to assess company performance. However, under growing global environmental awareness and corporate pursuit of sustainable development, using ratio analysis to evaluate operating performance can no longer provide a comprehensive comparison company performance. These kinds of assessment results do not reveal the actual situation of a company, and thus cannot serve as a helpful reference for investors and managers.

As a company becomes more competitive and begins to face the global market, it must cater to a wide range of consumer needs. Public pressure from consumers forces compa- 
nies to give up the pursuit of profit maximization. As a result, sustainable development has emerged as a way for companies, the environment, society and economic development to coexist. In order to gain community support and increase competitive advantage, corporate pursuit of sustainable development must take into account environmental protection and social development assistance. Therefore, in addition to considering corporate profits and survival, a complete concept of sustainable development should also include environmental, economic, and social dimensions. The three dimensions of sustainable development (environmental, economic and social) are often referred to as the triple bottom line (TBL) (Fauzi et al. 2010). Therefore, Elkington (1994) proposed that companies should pursue a TBL of sustainable development. The multiple dimensions of sustainable development are correlated with each other, making it difficult to choose, it is a multiple-criteria decision making (MCDM) problem.

MCDM is one of the most commonly used decision methods, and has been widely used in various fields such as management decisions, information project selection, supplier selection, and location selection (Hajeeh 2013; Khalili Esbouei et al. 2014; Safaei Ghadikolaei et al. 2014). There are a wide range of MCDM methods, each method with its own advantages and disadvantages. Therefore, Yoon and Hwang (1995) emphasized that policy makers should choose the right decision analysis methods. Many MCDM methods can be employed to solve decision-making problems, among which, the technique for order preference by similarity to ideal solution (TOPSIS) and Vlsekriterijumska Optimizacija I Kompromisno Resenje (VIKOR) methods are widely used to evaluate companies' performance (Moghassem 2013). However, the advantage of the TOPSIS method is that it is relatively simple and easy to use and understand. Thus, we choose TOPSIS as the ranking method to carry out corporate sustainability assessment.

In recent years, decision making trial and evaluation laboratory (DEMATEL) with analytic network process (ANP) (DEMATEL-based ANP, DANP) hybrid MCDM models have been widely used to solve performance evaluation problems (Peng, Tzeng 2013). DANP is a decision-making method which is combined with DEMATEL and ANP to solve influential weights of dependence and feedback problems. Among the current decision analysis methods, DEMATEL is the only method of analysis that divides complex factors into two groups, "cause" and "effect". Moreover, DEMATEL evaluates the relationship between any two elements according to the specific characteristics of the projectile-target, and figures out the causal relationships and impact strength of effects among all elements. ANP is a theory that extends the analytic hierarchy process (AHP) to determine the weight of each evaluation criterion. Integrated MCDM techniques combined with the DANP method have been successfully applied in many fields (Peng, Tzeng 2013).

In the literature, many studies have focused on the application of integrated DANPTOPSIS and DANP-VIKOR methods. Sustainable development performance evaluation is a kind of MCDM problem. Therefore, this article uses an integrated DANP-TOPSIS method as a tool for assessing corporate sustainability performance. However, previous studies have shown that integrated DANP-TOPSIS methods can only be used to analyze questionnaire data, and cannot be used to assess the quantity of secondary data. The 
grey relational analysis (GRA) is one of the commonly used methods included in the grey theory (Wei 2011). The GRA method analyzes the degree of correlation between two sequences, and has been widely used to examine the relationship between criteria. Therefore, this study uses GRA to calculate the degree of correlation between evaluation criteria. Then, we use DEMATEL to confirm the influential relation between evaluation perspectives. In this study, we propose a combined model called GRA-DEMATEL. After that, we use ANP to identify the weights for all evaluation criteria. Finally, the TOPSIS method can be used to evaluate and rank the sustainable development performance of companies. With the aim of fulfilling the above mentioned gap, this study proposes a hybrid TOPSIS model integrating GRA-DEMATEL, ANP, and TOPSIS methods as a decision making tool for evaluating a company's sustainable development performance based on the quantity of secondary data.

Taiwan's high-tech industry is competitive in the international market and is an important criterion of Taiwan's economy. Therefore, in order to verify the effectiveness of the proposed model, we use Taiwan's high-tech listed companies as the research object. The empirical results can guide companies' future business operations decisions (Wei et al. 2013) and can also serve as a reference for banks and investors when making credit and investment decisions.

\section{Literature review}

\subsection{Operational performance evaluation literature review}

In recent years, many studies have adopted expert opinion to identify indicators and criteria of financial performance evaluation. For example, Chaudhuri and Chowdhury (2012) proposed a multiple indicator, multiple cause (MIMIC) variable model to evaluate the financial performance of banks. Yalcin et al. (2012) applied fuzzy multi-criteria decision making methods for the financial performance evaluation of Turkish manufacturing industries.

However, traditional evaluation of financial performance is not an effective measure. In order to get a complete assessment of a company's performance it is necessary to consider both financial and non-financial performance. Therefore, previous studies offer different perspectives on the measurement of corporate performance. For example, Sheu and Lo (2005) evaluated corporate holistic performance including operational competence, financial health and environmental friendliness. Chavoshani et al. (2012) adopted traditional financial indices, and non-financial measurer indices to evaluate the performance of Telecommunications Company in Elam Province, Iran.

In recent years, under the growing international awareness of sustainable development, current market values have shifted from financial performance to achieve a balanced integration of economic, environmental and social dimensions of the TBL. Revenue and profit are no longer the sole drivers of multinational operators' strategic objectives. The focus has shifted instead to issues of corporate social responsibility (CSR) and their impact on sustainable competitive advantage and operating profit. Kocmanova and Docekalova (2011) mentioned that the use of classical or modern financial indicators 
of corporate economic performance for assessment of sustainability does not provide sufficient informative value. Fauzi et al. (2010) adopted the concept of TBL to assess sustainable corporate performance. Therefore, this study uses a TBL framework to measure the sustainable development performance of companies.

\subsection{Review of the methods of performance evaluation}

Traditional methods use financial ratio analysis to assess performance of a company. Researchers have also used data envelopment analysis (DEA) and balanced scorecards to measure company performance. However, M. K. Çetin and E. I. Çetin (2010) mentioned that the financial performance evaluation of companies is a MCDM problem. Pei et al. (2010) also mentioned that the TBL framework can be applied using a MCDM approach to evaluate sustainability. Therefore, this study uses the MCDM method to evaluate the sustainable development performance of companies.

In recent years, many researchers have combined DEMATEL, ANP and MCDM methods to measure and evaluate performance. For example, Lu et al. (2013) combined DEMATEL, ANP and VIKOR to evaluate the factors that influence the adoption of radio frequency identification (RFID) in Taiwan's healthcare industry. Wang and Tzeng (2012) used DEMATEL, ANP and VIKOR to evaluate brand marketing.

Several studies have also combined DANP and TOPSIS methods. For example, Büyüközkan and Çif̧̧i (2012) proposed an integrated method including DEMATEL, ANP and TOPSIS under a fuzzy environment to evaluate green suppliers. Uygun et al. (2013) combined DEMATEL, ANP and TOPSIS to evaluate and rank alternative suppliers.

However, the above evaluation methods mostly use questionnaire data or linguistic data to evaluate performance, and cannot be used for secondary data analysis. To compensate for this shortcoming, this study proposes an integrated model combining GRADEMATEL, ANP and TOPSIS methods for evaluating the sustainable development performance of companies.

\section{Methods}

This study integrates the GRA, DEMATEL, ANP and TOPSIS to construct a sustainable development performance evaluation model. These methods are described below.

\subsection{GRA-DEMATEL method}

The steps of the GRA-DEMATEL method are as follows:

Step1. Using GRA to obtain the grey relational matrix of evaluation criteria.

The GRA is the most widely used methods for determining the degree of correlation between two sequences. With the grey relational degree, we can identify relations among evaluation criteria. The grey relational degree can be divided into two types, localized and globalized grey relational grade. This study uses the globalized grey relational grade which is calculated as follows: 
(1). Grey relational generating. Grey relational generating is a process of sequencing data normalization. First set the original data sequence $x_{0}$ :

$$
x_{0}=\left(x_{0}(1), x_{0}(2), \cdots, x_{0}(n)\right) .
$$

Then, normalize by converting one of three measurements depending on the characteristics' criteria (Chiang, Hsieh 2009):

(a) The larger-the-better: The higher values reflect better performance:

$$
x_{i}^{*}(k)=\frac{x_{i}(k)-\min _{k} x_{i}(k)}{\max _{k} x_{i}(k)-\min _{k} x_{i}(k)},
$$

where $\max x_{i}(k)$ and $\min x_{i}(k)$ represent maximum and minimum values of $x_{i}(k)$, respectivekly, of the originall sequence $x_{0}$.

(b) The smaller-the-better: The lower values reflect better performance:

$$
x_{i}^{*}(k)=\frac{\max _{k} x_{i}(k)-x_{i}(k)}{\max _{k} x_{i}(k)-\min _{k} x_{i}(k)} .
$$

(c) The more nominal-the-better: The original data has a target optimum value $(o b)$ :

$$
x_{i}^{*}(k)=1-\frac{\left|x_{i}(k)-x_{o b}(k)\right|}{\max \left\{\max _{k} x_{i}(k)-x_{o b}(k), x_{o b}(k)-\min _{k} x_{i}(k)\right\}},
$$

where $x_{o b}(k)$ is the objective value of the $k_{t h}$ attribute, $\max _{k} x_{i}(k) \geq x_{o b}(k) \geq \min _{k} x_{i}(k)$. (2). Calculate the grey relational coefficient. The globalized GRA defined for each sequence can act as the reference sequence. The grey relational coefficient can be expressed as:

$$
\gamma\left(x_{i}(k), x_{j}(k)\right)=\frac{\Delta_{\min }+\zeta \Delta_{\max } \cdot}{\Delta_{i j}(k)+\zeta \Delta_{\max }},
$$

where $x_{i}(k)=\left(x_{i}(1), x_{i}(2), \cdots, x_{i}(k)\right) \in X, \Delta_{i j}(k)=\left|x_{i}(k)-x_{j}(k)\right|$ is the absolute value of the difference between $x_{i}$ and $x_{j}$ at the $k_{t h}$ attribute, $\Delta_{\min }=\min _{\forall j \in i} \min _{\forall k}\left|x_{i}(k)-x_{j}(k)\right|$, $\Delta_{\max }=\max _{\forall j \in i} \max _{\forall k}\left|x_{i}(k)-x_{j}(k)\right|, \zeta$ is the distinguishing or identified coefficient and $\zeta \in[0,1]$. In general, the value of $\zeta$ can be set to 0.5 . $\gamma\left(x_{i}(k), x_{j}(k)\right)$ represents the grey relational coefficient.

(3). Calculate the grey relational grade. The grey relational grade is calculated by averaging the grey relational coefficient corresponding to each performance characteristic:

$$
\gamma_{i j}=\frac{1}{n} \sum_{k=1}^{n} \gamma\left(x_{i}(k), x_{j}(k)\right),
$$

where $\gamma_{i j}$ is the grey relational grade between $x_{i}$ and $x_{j}$. 
(4). Calculate the grey relational matrix. By calculating all of the grey relational grades (Eq. (6)), we can establish a grey relational matrix. The grey relational matrix $R$ is defined as follows:

$$
R_{m \times m}=\left[\begin{array}{ccccc}
\gamma_{11} & \gamma_{12} & \gamma_{13} & \cdots & \gamma_{1 m} \\
\gamma_{21} & \gamma_{22} & \gamma_{23} & \cdots & \gamma_{2 m} \\
\gamma_{31} & \gamma_{32} & \gamma_{33} & \cdots & \gamma_{3 m} \\
\vdots & \vdots & \vdots & \vdots & \vdots \\
\gamma_{m 1} & \gamma_{m 2} & \gamma_{m 3} & \cdots & \gamma_{m m}
\end{array}\right] .
$$

Step 2. Generating the direct-relation matrix.

According to the concept of the DEMATEL method, if we know the degree of influence, we can use a matrix to illustrate the relationship between criteria. Supposing there are $\mathrm{m}$ factors, the criteria are compared based on their relation and degree of influence to get the $m \times m$ matrix, which is called the direct-relation matrix and is expressed by $\mathrm{T}$. In this study, we follow the above concept of the grey correlation matrix (Eq. (7)) as a direct-relation matrix in DEMATEL, and self-correlation is set to $0 . \gamma_{i j}$ represents the degree of influence of criterion $i$ on criterion $j$. Therefore,

$$
T=\left[\begin{array}{ccccc}
0 & \gamma_{12} & \gamma_{13} & \cdots & \gamma_{1 m} \\
\gamma_{21} & 0 & \gamma_{23} & \cdots & \gamma_{2 m} \\
\gamma_{31} & \gamma_{32} & 0 & \cdots & \gamma_{3 m} \\
\vdots & \vdots & \vdots & \vdots & \vdots \\
\gamma_{m 1} & \gamma_{m 2} & \gamma_{m 3} & \cdots & 0
\end{array}\right]
$$

Step 3. Calculation of the standardized direct-relation matrix.

The direct-relation matrix $T$ is multiplied by $\lambda$, that is, $X=\lambda \cdot T$, to obtain the standardized direct-relation matrix $X$, where

$$
\lambda=\frac{1}{\max _{1 \leq i \leq m}\left(\sum_{j=1}^{m} \gamma_{i j}\right)} .
$$

Step 4. Calculation of the direct/indirect matrix (total-relation matrix).

The direct/indirect matrix $Z$ can be obtained as follows:

$$
Z=\lim _{k \rightarrow \infty}\left(X+X^{2}+\cdots+X^{k}\right)=X(I-X)^{-1},
$$

where $I$ is the identity matrix.

\subsection{Using GRA-DEMATEL based on ANP to determine the influence of weights}

The ANP, proposed by Saaty (1996), is an extension of AHP for typical network systems. It mainly aims to determine relationships of nonlinear and network shape, and uses ratio scale measurements to obtain more accurate weights between criteria. This 
study presents a GRA-DEMATEL based ANP model for determining the criteria weight. The operation steps are described as follows:

Step 1. First, the results of GRA-DEMATEL (Eq. (10)) are used to construct the totalinfluence matrix $Z$. Then, by applying Eq. (11) for normalization, we can obtain the normalized total-influence matrix $T_{Z}$ :

$$
\begin{gathered}
\gamma_{i j}^{Z}=\frac{\gamma_{i j}^{P}}{\sum_{i=1}^{m} \gamma_{i j}^{P}}, \\
T_{Z}=\left[\begin{array}{ccccc}
\gamma_{11}^{Z} & \cdots & \gamma_{1 j}^{Z} & \cdots & \gamma_{1 m}^{Z} \\
\vdots & & \vdots & & \vdots \\
\gamma_{i 1}^{Z} & \cdots & \gamma_{i j}^{Z} & \cdots & \gamma_{i m}^{Z} \\
\vdots & & \vdots & \vdots & \vdots \\
\gamma_{m 1}^{Z} & \cdots & \gamma_{m j}^{Z} & \cdots & \gamma_{m m}^{Z}
\end{array}\right] .
\end{gathered}
$$

Step 2. Divide the total-influence matrix $Z$ by the sum of influence for each criterion to obtain the unweighted supermatrix $W$.

Step 3. The weighted supermatrix $W_{W}$ can be calculated by multiplying the unweighted supermatrix $W$ and the normalized total-influence matrix $T_{Z}$.

Step 4. The limit supermatrix (shown in Eq. (13)) is obtained by multiplying the unweighted supermatrix $W$ by itself multiple times:

$$
\lim _{g \rightarrow \infty}\left(W_{w}\right)^{g}
$$

where $g$ is an arbitrary number. Then, each row of the limit supermatrix is taken as the weight of each criterion.

\subsection{The TOPSIS method}

TOPSIS is a multi-criteria decision analysis method, which was developed by Hwang and Yoon (1981). It is a common and simple evaluation method, which uses the distance between the ideal solution and the negative ideal solution as a basis to rank the evaluation objects. Therefore, this study adopts the TOPSIS method to conduct corporate sustainability performance evaluation and ranking. A shortcoming of TOPSIS is that it uses subjective weight. To make up for this, the weights used in our model come from the results of the proposed GRA-DEMATEL based ANP method. The steps of the TOPSIS method are summarized as follows:

Step 1. Calculate the normalized decision matrix $R=\left[r_{i j}\right]_{m \times n}$. Suppose there are $m$ alternatives to be evaluated and $n$ evaluation attributes. Because financial criteria are either benefit or cost criterion, and there may be a negative value. To avoid these problems, we use Eqs. (2) to (4) to normalize the original data that all data are normalized between 0 and 1 . 
Step 2. Calculate the weighted normalized decision matrix $V=\left[v_{i j}\right]_{m \times n}$. The weighted normalized value $v_{i j}$ is calculated as follows:

$$
v_{i j}=\left(w_{i j}\right)\left(r_{i j}\right),
$$

where $i=1,2, \ldots, m, j=1,2, \ldots, n, w_{j}$ is the $j$ th attribute weighting value from GRADEMATEL based ANP method, $\sum_{j=1}^{n} w_{j}=1$.

Step 3. Determine positive and negative-ideal solution, $A^{+}$and $A^{-}$, respectively:

$$
\begin{aligned}
& A^{+}=\left\{v_{1}^{+}, v_{2}^{+}, \ldots, v_{n}^{+}\right\}=\left\{\left(\max _{i} v_{i j} \mid j \in J\right),\left(\min _{i} v_{i j} \mid j \in J^{\prime}\right), i=1,2, \cdots, m\right\}, \\
& A^{-}=\left\{v_{1}^{-}, v_{2}^{-}, \ldots, v_{n}^{-}\right\}=\left\{\left(\min _{i} v_{i j} \mid j \in J\right),\left(\max _{i} v_{i j} \mid j \in J^{\prime}\right), i=1,2, \cdots, m\right\},
\end{aligned}
$$

where $J$ is a set of benefit attributes and $J^{\prime}$ is a set of cost attributes.

Step 4. Calculate the separation measures using the Euclidean distance. The separations from the positive ideal solution $S_{i}^{+}$and the negative ideal solution $S_{i}^{-}$are given as follows:

$$
\begin{aligned}
& S_{i}^{+}=\sqrt{\sum_{j=1}^{n}\left(v_{i j}-v_{j}^{+}\right)^{2}}, i=1,2, \ldots, m, \\
& S_{i}^{-}=\sqrt{\sum_{j=1}^{n}\left(v_{i j}-v_{j}^{-}\right)^{2}}, i=1,2, \ldots, m .
\end{aligned}
$$

Step 5. Calculate the relative closeness to the ideal solution by $C_{i}$ :

$$
C_{i}=\frac{S_{i}^{-}}{S_{i}^{+}+S_{i}^{-}}, i=1,2, \ldots, m .
$$

Step 6. Rank the alternatives according to $C_{i}$, where a higher $C_{i}$ value means higher preference.

\subsection{Sensitivity analysis}

Weights of criteria have significant influence on TOPSIS results. For the purpose of investigating the effect of changes in criteria weights on the TOPSIS results, this study uses sensitivity analysis. Moghassem (2013) increased or decreased all criteria weights by $5 \%, 10 \%, 15 \%$, and $20 \%$ to conduct sensitivity analysis. In this study, sensitivity analysis is done by increasing top three criteria weights values by $10 \%$ or decreasing the last three criteria weights values by $10 \%$.

\section{Definition of evaluation categories and criteria}

This study uses the environmental, economic and social aspects of the TBL as the three criteria of sustainable development performance evaluation. The three categories of sustainable development performance are described as follows. 


\subsection{Economic performance}

In general, companies can apply financial or non-financial criteria to measure operating performance. Piotroski (2000) stated that financial signals can be divided into three categories: profitability, liquidity/leverage and operating efficiency. Therefore, we used the ratio analysis to evaluate financial performance. In this study, seven of the common financial ratios used as criteria for financial performance evaluation, including the current ratio $(\mathrm{CR})$, quick ratio $(\mathrm{QR})$, return on assets (ROA), return on equity (ROE), gross profit margin (GPM), operating margin (OM), inventory turnover (IT), and accounts receivable turnover (ART) that obtained from the three categories (solvency, profitability, and operating ability).

Many scholars have suggested that performance measures should integrate both financial and non-financial measures, in order to achieve the balance between short-term benefits and long-term competitive advantage. Therefore, we also consider non-financial criteria, such as measures of financial risk, including the degree of operating leverage (DOL) and degree of financial leverage (DFL), and measures of the return earned: RAROC. However, companies must continue to maintain competitiveness through innovation and R\&D investment to improve business performance and achieve sustainable development goals. Therefore, R\&D expenditure (RDE) and total sales (TS) were also selected as evaluation criteria.

\subsection{Environmental performance}

The amount of environmental expenditure can reveal the extent of a company's investment in environmental protection, and current state of resource allocation and status. For better environmental performance, a company's annual reports and CSR reports disclose more information related to environmental management and environmental policy. Therefore, in order to achieve the goal of sustainable development, a company's environmental information should be voluntarily provided in order to enhance the value of the company. As such, this study uses environmental expenditure (EE) and environmental information disclosure (EID) as measures of corporate sustainable development evaluation.

In recent years, eco-efficiency indices can provide descriptions of the environmental performance of a company and the value generated. Such indices are important tools for governments, the general public, investors and financial institutions to assess the environmental performance of companies. Usually, an eco-efficiency index is calculated by the ratio of product or service value divided by the environmental influence. This study takes energy consumption, water consumption, waste generation and emissions of greenhouse gases as measures of environmental influence, and an eco-efficiency index (EEI) is used as one of the measures of the environmental performance of companies.

\subsection{Social performance}

Social influence is not a simple and clear measure of a company's financial situation through which profit and loss figures can be fully understood. Corporate social responsibility is not only an issue of the business community's expectations, but also a question 
of a company's brand image. Especially due to the impact of the global financial crisis, only by fulfilling social responsibility can a company reach the important cornerstone of sustainable development. A CSR report shows a company's strategy and practices for sustainable development. Moreover, the measure of CSR has been used in many studies to measure corporate social performance. Therefore, the measure of CSR is tracked as a proxy of social performance. However, there is a lack of adequate information regarding CSR measures in Taiwan. Nonetheless, companies that disclose CSR report information can establish a way of communicating with interested parties to convey the concept of sustainable development. Zeghal and Ahmed (1990) used the number of words disclosed in CSR reports as the measure of CSR disclosure. Therefore, we adopt a logarithm based on the numbers of words disclosed in CSR reports (CSRD) as a social performance measurement criterion.

\section{An empirical study}

\subsection{Sample and data source}

In Taiwan, the concept of corporate sustainable development is just beginning to form. Until 2014, in Taiwan's Gretai Securities Market CSR database, only 99 listed companies disclosed corporate social responsibility reports. This study uses Taiwanese hightech listed companies as the research sample. After excluding companies with incomplete information, a total of 34 high-tech listed companies (Company F1 to F34) were selected in this study. Sustainability performance categories cover economic (13 criteria), environmental ( 3 criteria) and social ( 1 criterion) criteria, with a total of 17 selected criteria. The data were obtained from each company's CSR report, financial statements and annual reports in 2013. Data sources of finance, operation, environmental and social criteria include the Taiwan Economic Journal Data Bank (TEJ), eco-efficiency indexes, environmental and CSR disclosures collected from CSR reports, and RAROC values provided by the TEJ VaR system v2.1.

\subsection{Measuring relationships between criteria using the GRA-DEMATEL technique}

Before carrying out empirical analysis, in order to meet the requirements of the comparability of data, we need to normalize the original data in accordance with this property. The 17 criteria, apart from the degree of operating leverage and the degree of financial leverage, can be classified as lower-bound effectiveness measures. The other criteria are upper-bound effectiveness measure. According to Eqs. (1) to (4), convert CR, QR, ROA, ROE, GPM, OM, IT, ART, DOL, DFL, RAROC, RDE, TS, EE, EID, EEI, and CSRD criteria, where the normalized matrix is defined as:

$$
X^{*}=\left[\begin{array}{cccc}
0.5975 & 0.6370 & \cdots & 0.4871 \\
0.4041 & 0.3859 & \cdots & 0.6569 \\
\vdots & \vdots & \vdots & \vdots \\
0.4493 & 0.3973 & \cdots & 0.5793
\end{array}\right] .
$$


Then, calculate the grey relational degree and grey relational coefficient according to Eq. (5) and (6). Finally, using Eq. (7), obtain the grey relational matrix,

$$
R_{17 \times 17}=\left[\begin{array}{ccccc}
1 & 0.9336 & 0.6786 & \cdots & 0.5775 \\
0.9336 & 1 & 0.6646 & \cdots & 0.5521 \\
0.6471 & 0.6323 & 1 & \cdots & 0.6655 \\
\vdots & \vdots & \vdots & \vdots & \vdots \\
0.5535 & 0.5267 & 0.6741 & \cdots & 1
\end{array}\right] .
$$

Next, convert the value of 1 to 0 on the diagonal of the grey relational matrix. We can obtain the direct-relation matrix $T$. According to DEMATEL method, the total-relation matrix $Z$ can be obtained from Eqs. (8) to (10),

$$
Z_{17 \times 17}=\left[\begin{array}{ccccc}
1.0989 & 1.1728 & 1.1491 & \cdots & 1.0392 \\
1.1738 & 1.0927 & 1.1452 & \cdots & 1.0346 \\
1.0959 & 1.0911 & 1.0354 & \cdots & 0.9958 \\
\vdots & \vdots & \vdots & \vdots & \vdots \\
1.0001 & 0.9947 & 1.0052 & \cdots & 0.8605
\end{array}\right] .
$$

\subsection{Deriving the weights of criteria by the GRA-DEMATEL based ANP technique}

By applying GRA-DEMATEL technique, we can obtain the total impact matrixes of the 17 criteria. Then ANP can be used to obtain the relative weights of the 17 criteria. Applying Eqs. (11) to (13), we can obtain the unweighted supermatrix, weighted supermatrix and the limiting power of the weighted supermatrix, as well as the weights of each criterion. In this study, Super Decisions software (Saaty 1996) was used to calculate the weights of the 17 criteria based on ANP technique.

Results of the total impact matrix that obtained from GRA-DEMATEL technique are input into the Super Decision software, which is able to calculate the weighted supermatrix,

$$
W_{W}=\left[\begin{array}{ccccc}
0.0591 & 0.0620 & 0.0621 & \cdots & 0.0627 \\
0.0538 & 0.0513 & 0.0549 & \cdots & 0.0536 \\
0.0581 & 0.0592 & 0.0554 & \cdots & 0.0581 \\
\vdots & \vdots & \vdots & \vdots & \vdots \\
0.0620 & 0.0610 & 0.0613 & \cdots & 0.0584
\end{array}\right] .
$$

Using the Super Decisions software, we can be easily to get the limit supermatrix. The limit supermatrix shows the relative weight of 17 criteria. The weights of 17 criteria given by the limit supermatrix are shown in Table 1 . 
Table 1. Criteria weights in the limit supermatrix

\begin{tabular}{cccccccccc}
\hline Criteria & CR & QR & ROA & ROE & GPM & OM & IT & ART & DOL \\
\hline Weights & 0.0622 & 0.0620 & 0.0590 & 0.0614 & 0.0608 & 0.0598 & 0.0604 & 0.0586 & 0.0604 \\
\hline Criteria & DFL & RAROC & RDE & TS & EE & EID & EEI & CSRD & \\
\hline Weights & 0.0528 & 0.0574 & 0.0599 & 0.0593 & 0.0560 & 0.0582 & 0.0579 & 0.0540 & \\
\hline
\end{tabular}

Note: CR: current ratio, QR: quick ratio, ROA: return on assets, ROE: return on equity, GPM: gross profit margin, OM: operating margin, IT: inventory turnover, ART: accounts receivable turnover, DOL: degree of operating leverage, DFL: degree of financial leverage, RAROC: risk-adjusted return on capital, RDE: R\&D expenditure, TS: total sales, EE: environmental expenditure, EID: environmental information disclosure, EEI: eco-efficiency index, CSRD: disclosed in CSR reports.

\subsection{The results of combining GRA-DEMATEL based ANP and TOPSIS method}

The objective of this study is to construct a hybrid TOPSIS model to provide comprehensive evaluating and ranking of the sustainable development performance of 34 high-tech companies in Taiwan. First, this study combined GRA-DEMATEL and ANP to obtain the weights of 17 sustainable development performance evaluation criteria. Then, we further integrated TOPSIS method to evaluate and rank the sustainable development performance these 34 high-tech listed companies.

Because the 17 evaluation criteria include both benefit criteria and cost criteria, we may get some negative values. To avoid this problem, the original data were normalized using Eqs. (2) to (4) so that all data are normalized between 0 and 1. Among the 17 criteria, DOL and DFL are the smaller-the-better (cost criteria), which the rest of the variables are the larger-the-better (benefit criteria). Therefore, we normalize the original data and establish the normalized decision matrix $R$. We replace the value of matrix $R$ with the value of the matrix $X^{*}$ as the normalized decision matrix to rank the 34 hightech listed companies.

In this study, we develop a GRA-DEMATEL based ANP technique to obtain weights for each criterion, as shown in Table 1 . Then by multiplying the normalized decision matrix with its relative weight, we can obtain weighted normalized decision matrix $V$ :

$$
V=\left[\begin{array}{cccc}
0.0372 & 0.0395 & \cdots & 0.0263 \\
0.0251 & 0.0239 & \cdots & 0.0355 \\
\vdots & \vdots & \vdots & \vdots \\
0.0279 & 0.0246 & \cdots & 0.0313
\end{array}\right]_{34 \times 17}
$$

Eq. (15) and (16) are used to determine the positive ideal solution $\left(A^{+}\right)$and negative ideal solution $\left(A^{-}\right)$for which $A^{+}=[0.0622,0.062,0.059, \cdots, 0.0540]_{1 \times 17}, A^{-}=[0,0$, $0, \cdots, 0]_{1 \times 17}$. Then we calculate the distance between each criterion (using Eqs. (17) and (18)) and the relative closeness coefficients (using Eq. (19)), as shown in Table 2. 
Table 2. The distance measure, relative closeness coefficient and ranking

\begin{tabular}{cccccccccc}
\hline Companies & $S_{i}^{+}$ & $S_{i}^{-}$ & $C_{i}$ & Rank & Companies & $S_{i}^{+}$ & $S_{i}^{-}$ & $C_{i}$ & Rank \\
\hline F1 & 0.1638 & 0.1138 & 0.4100 & 19 & F18 & 0.1469 & 0.1324 & 0.4739 & 2 \\
\hline F2 & 0.1573 & 0.1217 & 0.4363 & 8 & F19 & 0.1560 & 0.1185 & 0.4318 & 11 \\
\hline F3 & 0.1731 & 0.1018 & 0.3702 & 25 & F20 & 0.1533 & 0.1172 & 0.4333 & 10 \\
\hline F4 & 0.1524 & 0.1191 & 0.4386 & 7 & F21 & 0.1952 & 0.0775 & 0.2841 & 34 \\
\hline F5 & 0.1601 & 0.1116 & 0.4107 & 18 & F22 & 0.1403 & 0.1263 & 0.4736 & 3 \\
\hline F6 & 0.1419 & 0.1241 & 0.4666 & 5 & F23 & 0.1548 & 0.1094 & 0.4141 & 17 \\
\hline F7 & 0.1532 & 0.1236 & 0.4465 & 6 & F24 & 0.0977 & 0.1865 & 0.6564 & 1 \\
\hline F8 & 0.1540 & 0.1157 & 0.4291 & 13 & F25 & 0.1744 & 0.0903 & 0.3410 & 29 \\
\hline F9 & 0.1854 & 0.0868 & 0.3188 & 32 & F26 & 0.1786 & 0.0923 & 0.3407 & 30 \\
\hline F10 & 0.1654 & 0.1208 & 0.4220 & 15 & F27 & 0.1601 & 0.1059 & 0.3980 & 22 \\
\hline F11 & 0.1545 & 0.1114 & 0.4189 & 16 & F28 & 0.1675 & 0.1240 & 0.4255 & 14 \\
\hline F12 & 0.1410 & 0.1235 & 0.4667 & 4 & F29 & 0.1835 & 0.0859 & 0.3189 & 31 \\
\hline F13 & 0.1930 & 0.0853 & 0.3065 & 33 & F30 & 0.1588 & 0.1196 & 0.4297 & 12 \\
\hline F14 & 0.1622 & 0.1081 & 0.4000 & 21 & F31 & 0.1689 & 0.0958 & 0.3619 & 26 \\
\hline F15 & 0.1638 & 0.1263 & 0.4352 & 9 & F32 & 0.1734 & 0.1138 & 0.3962 & 23 \\
\hline F16 & 0.1673 & 0.1007 & 0.3756 & 24 & F33 & 0.1718 & 0.1182 & 0.4076 & 20 \\
\hline F17 & 0.1722 & 0.0958 & 0.3575 & 27 & F34 & 0.1737 & 0.0921 & 0.3464 & 28 \\
\hline
\end{tabular}

\subsection{The results of sensitivity analysis}

This study uses sensitivity analysis to understand whether the empirical results are significantly affected by the criteria weights. The sensitivity analysis was done by varying the weighting values of the top 3 (increase 10\%) and the lowest 3 (decrease 10\%) criteria. The other criteria remained unchanged. The results of sensetivity analysis are shown in Table 3. In order to investigate whether the ranking results of the changes in the weight of TOPSIS have a significant correlation with original TOPSIS, the Spearman and Kendall rank correlation test was used in this study to examine the correlation of two rankings (Ball, Korukoğlu 2014; Chakraborty et al. 2013). The Spearman (Kendall) correlation coefficient between the changes in the weight of hybrid TOPSIS (Table 3) and the original hybrid TOPSIS (Table 2) are $0.986(0.922)$. This means that a positive and strong relationship exists between the two rankings. That is, we found that changing the weights had little effect on the empirical results of the proposed hybrid TOPSIS.

Table 3. Sensitivity analysis results based on a hybrid TOPSIS model for ranking

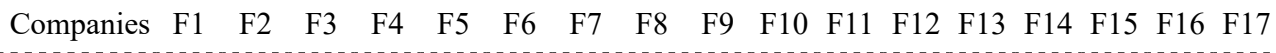

$\begin{array}{llllllllllllllllll}\text { Rank } & 14 & 8 & 25 & 9 & 19 & 3 & 7 & 16 & 32 & 17 & 15 & 4 & 33 & 22 & 6 & 24 & 27\end{array}$

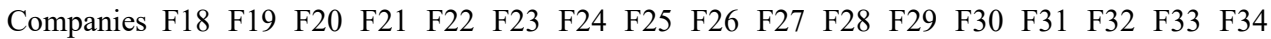

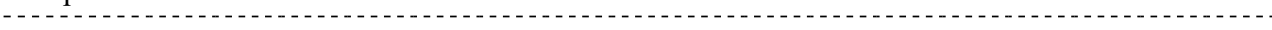

$\begin{array}{llllllllllllllllll}\text { Rank } & 2 & 13 & 10 & 34 & 5 & 18 & 1 & 30 & 29 & 23 & 11 & 31 & 12 & 26 & 20 & 21 & 28\end{array}$




\section{Conclusions and future work}

Both the financial crisis and global warming have shown companies that the targets of operation are no longer just short-term profits and high performance. In fact, sustainable development is the only option for the future. The issues of sustainable development, with recent dramatic climate change, rapid depletion of natural resources and the increasing frequency of natural disasters, has become one of the important topics of modern enterprise management. Therefore, establishing a comprehensive evaluation model as the basis for governments, the general public, investors, and financial institutions to assess a company's sustainable development performance is currently a very important issue.

A DANP based TOPSIS method can only be used in a questionnaire and cannot be used for quantitative data. In order to make up for this shortage, this study proposed a TOPSIS method combining GRA and DANP designed for the analysis of quantitative data. To validate the proposed hybrid TOPSIS method, we selected 34 of Taiwan's high-tech listed companies as the research object. According to the triple bottom line consisting of economic, environmental and social categories as the basis for sustainable development measurement, 17 evaluation criteria were selected to evaluate and rank the sustainable development performance of the 34 companies in 2013. Empirical results were made available to the companies as a basis for improvement, but also as a useful reference tool for investors and banks.

First, this study combined GRA with DEMATEL to measure the correlation between the selected criteria and then integrated ANP to calculate the 17 criteria weights. Finally, TOPSIS was applied to obtain the sustainable development performance evaluation and ranking of 34 high-tech listed companies in Taiwan. According to the results of weight value calculation, the three most important criteria of a company's sustainable development performance are ROE, CR, and QR. The companies' sustainable development performance evaluation results show that the top three companies are companies F24, F18, and F22, and the worst three companies are companies F9, F13, and F21. This study proposes a hybrid TOPSIS model which can be used as a basis for evaluating companies' sustainable development performance and as a reference for sustainable management.

The concept of corporate sustainable development has been the focus of attention of the general investing public. A company in pursuit of profit, must take responsibility for social and environmental impact, and play the role of good corporate citizen in order to create a sustainable competitive advantage.

However, this study has some limitations that need to be mentioned. First, there were only three criteria were chosen, and used in sustainable development performance evaluation that did not consider all of the criteria. Therefore, future researcher may consider other criteria such as industrial characteristic, strategic and operating risk management. Second, in this study only a few criteria were considered as the measure of environmental and social performance. This will cause the company's sustainable development performance is strongly dominated by the economic performance of criteria. Therefore, more environmental and social criteria should be taken into consideration by future researchers. Third, we did not include the qualitative criteria to evaluate company's 
sustainable development performance. Thus, we provide suggestions for future research that combining quantitative and qualitative criteria in evaluation research. However, although there were some limitations of this study mentioned above, but company's sustainable development performance evaluation is a topic worthy of further discussion and investigation.

\section{References}

Ball, S.; Korukoğlu, S. 2014. Development of a fuzzy decision support framework for complex multi-attribute decision problems: a case study for the selection of skilful basketball players, Expert Systems 31(1): 56-69. http://dx.doi.org/10.1111/exsy.12002

Büyüközkan, G.; Çifçi, G. 2012. Evaluation of the green supply chain management practices: a fuzzy ANP approach, Production Planning and Control 23(6): 405-418.

http://dx.doi.org/10.1080/09537287.2011.561814

Çetin, M. K.; Çetin, E. I. 2010. Multi-criteria analysis of banks' performances, International Journal of Economics and Finance Studies 2(2): 73-78.

http://dx.doi.org/10.7763/IJTEF.2014.V5.391

Chakraborty, R.; Ray, A.; Dan, P. 2013. Multi criteria decision making methods for location selection of distribution centers, International Journal of Industrial Engineering Computations 4(4): 491-504. http://dx.doi.org/10.5267/j.ijiec.2013.06.006

Chaudhuri, K.; Chowdhury, T. 2012. Financial performance evaluation: a structural equation approach, Journal of Emerging Market Finance 11(1): 1-36.

http://dx.doi.org/10.1177/097265271101100101

Chavoshani, M.; Jamshidinavid, B.; Mirzae, K. 2012. A performance evaluation of telecommunications company in Province of Elam based on balanced score card (BSC) from 2006 to 2011, Journal of Advanced Social Research 2(4): 202-214. [online], [cited 7 February 2015]. Available from Internet: http://www.sign-ific-ance.co.uk/dsr/index.php/JASR/article/view/287/292

Chiang, Y. M.; Hsieh, H. H. 2009. The use of the Taguchi method with grey relational analysis to optimize the thin-film sputtering process with multiple quality characteristic in color filter manufacturing, Computers \& Industrial Engineering 56(2): 648-661.

http://dx.doi.org/10.1016/j.cie.2007.12.020

Elkington, J. 1994. Towards the sustainable corporation: win-win-win business strategies for sustainable development, California Management Review 36(2): 90-100.

http://dx.doi.org/10.2307/41165746

Fauzi, H.; Svensson, G.; Rahman, A. A. 2010. "Triple Bottom Line" as "Sustainable Corporate Performance": a proposition for the future, Sustainability 2(5): 1345-1360.

http://dx.doi.org/10.3390/su2051345

Hajeeh, M. A. 2013. Application of fuzzy multi-criteria decision making in R\&D project manager selection, International Journal of Information Technology Project Management (IJITPM) 4(2): 35-49. http://dx.doi.org/10.4018/jitpm.2013040103

Hwang, C. L.; Yoon, K. 1981. Multiple attribute decision making methods and applications. Berlin: Springer-Verlag.

Khalili Esbouei, S.; Safaei Ghadikolaei, A.; Antucheviciene, J. 2014. Using FANP and fuzzy VIKOR for ranking manufacturing companies based on their financial performance, Economic Computation and Economic Cybernetics Studies and Research 48(3): 141-162 [online], [cited 12 August 2015]. Available from Internet: http://www.ecocyb.ase.ro/eng/Articles_3-2014/Saber\%20 K.\%20ESBOUEI\%20,\%20Jurgita\%20ANTUCHEVICIENE.pdf

Kocmanova, A.; Docekalova, M. 2011. Corporate sustainability: environmental, social, economic and corporate performance, Acta Universitatis Agriculturae et Silviculturae Brunensis 2011(7): 203-209. http://dx.doi.org/10.11118/actaun201159070203 
Lu, M. T.; Lin, S. W.; Tzeng, G. H. 2013. Improving RFID adoption in Taiwan's healthcare industry based on a DEMATEL technique with a hybrid MCDM model, Decision Support Systems 56: 259-269. http://dx.doi.org/10.1016/j.dss.2013.06.006

Moghassem, A. R. 2013. Comparison among two analytical methods of multi-criteria decision making for appropriate spinning condition selection, World Applied Sciences Journal 21(5): 784-794. http://dx.doi.org/10.5829/idosi.wasj.2013.21.5.80

Pei, Y.; Amekudzi, A.; Meyer, M.; Barrella, E.; Ross, C. 2010. Performance measurement frameworks and development of effective sustainable transport strategies and indicators, Transportation Research Record: Journal of the Transportation Research Board No. 2163. Washington, DC: Transportation Research Board of the National Academies, 73-80.

http://dx.doi.org/10.3141/2163-08

Peng, K. H.; Tzeng, G. H. 2013. A hybrid dynamic MADM model for problem-improvement in economics and business, Technological and Economic Development of Economy 19(4): 638-660. http://dx.doi.org/10.3846/20294913.2013.837114

Piotroski, J. D. 2000. Value investing: the use of historical financial statement information to separate winners from losers, Journal of Accounting Research 38: 1-41.

http://dx.doi.org/10.2307/2672906

Saaty, T. L. 1996. Decision making with dependence and feedback: the analytic network process. Pittsburgh: RWS publications.

Safaei Ghadikolaei, A.; Khalili Esbouei, S.; Antucheviciene, J. 2014. Applying fuzzy MCDM for financial performance evaluation of Iranian companies, Technological and Economic Development of Economy 20(2): 274-291. http://dx.doi.org/10.3846/20294913.2014.913274

Sheu, H. J.; Lo, S. F. 2005. A new conceptual framework integrating environment into corporate performance evaluation, Sustainable Development 13: 79-90. http://dx.doi.org/10.1002/sd.247

Uygun, Ö.; Kaçamak, H.; Ayşim, G.; Şimşir, F. 2013. Supplier selection for automotive industry using multi-criteria decision making techniques, TOJSAT: The Online Journal of Science and Technology 3(4): 126-137.

Wang, Y. L.; Tzeng, G. H. 2012. Brand marketing for creating brand value based on a MCDM model combining DEMATEL with ANP and VIKOR methods, Expert Systems with Applications 39: 5600-5615. http://dx.doi.org/10.1016/j.eswa.2011.11.057

Wei, G. W. 2011. Grey relational analysis model for dynamic hybrid multiple attribute decision making, Knowledge-Based Systems 24(5): 672-679.

http://dx.doi.org/10.1016/j.knosys.2011.02.007

Wei, G. W.; Zhao, X.; Lin, R. 2013. Some hybrid aggregating operators in linguistic decision making with Dempster-Shafer belief structure, Computers \& Industrial Engineering 65(4): 646651. http://dx.doi.org/10.1016/j.cie.2013.05.011

Yalcin, N.; Bayrakdaroglu, A.; Kahraman, C. 2012. Application of fuzzy multi-criteria decision making methods for financial performance evaluation of Turkish manufacturing industries, Expert Systems with Applications 39(1): 350-364. http://dx.doi.org/10.1016/j.eswa.2011.07.024

Yoon, K. P.; Hwang, C. L. 1995. Multiple attribute decision making: an introduction. Thousand Oaks, CA: Sage Publications.

Zeghal, D.; Ahmed, S. A. 1990. Comparison of social responsibility information disclosure media used by Canadian firms, Accounting, Auditing \& Accountability Journal 3(1): 38-53. http://dx.doi.org/10.1108/02686901011054881

Yih-Chang OU is an assistant professor of statistics at Ling Tung University, Taiwan. He received his Ph.D. in biometry from National Taiwan University, Taiwan. His research areas are decision making theory, grey system theory, generalized linear model theory and practice, risk management and investment management. His articles are published by Journal of Business Economics and Management, Journal of Applied Statistics, International Journal of Economics and Finance, and others. 